\title{
An Efficient DC-DC Converter for PV and Battery Applications
}

\author{
Rakesh M S ${ }^{1}, K$. Vasudev Shettigar ${ }^{2}$ \\ PG Scholar, E\&E Department, NMAMIT, Nitte, India ${ }^{1}$ \\ Associate Professor, E\&E Department, NMAMIT, Nitte, India ${ }^{2}$
}

\begin{abstract}
This paper presents the power electronic circuits for PV panel and Local energy storage system (i.e. Battery). The power converter is a three port non isolated DC-DC converter with (I) unidirectional port for PV panel and (II) Bidirectional port for battery (Charging and Discharging).PV arrays are operating in low voltage range and for low generating power system, in order to extract high power and also to connect them with large voltage DC bus, power electronic converter are very essential and useful. To analyze all the different modes of operating conditions and designing the power converter circuit, a theoretical calculation are carried out and which are given in the form of main equations. This analysis is compared with simulation result to validate the proposed system, and is simulated in MATLAB SIMULINK for low wattage of power.
\end{abstract}

Keywords: Power electronic step up-step down converter, Local energy storage system, PV panel, three port DC-DC converter.

\section{INTRODUCTION}

The electricity requirement has been increasing every day. The power generation from the fossil fuels is not sufficient to satisfy the required load demand, so we are looking to the renewable energy sources such as solar energy, wind etc. among them solar energy is one of the most available and clean energy around the world. Once we know the right technology it's very easy to harvest the solar energy. However the grid voltage is negatively affected by increasing number of distributed energy sources. However in some case PV inverter has lags will connecting to the grid, this is not a reason for PV inverter has less reliable. Grid with high injected power from PV plant will activates very high grid voltage in customer electricity device installation.

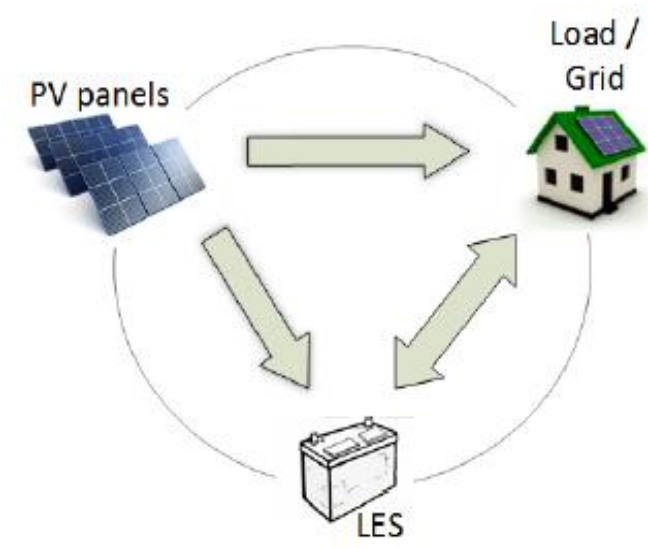

Fig.1. Power flow for a PV system with LES and grid support
A local energy storage system can support the electricity grid. Later days when PV power is lower than these local energy storage systems can supply the required electricity to the electric grid and also supplies to the consumer over those days, hence decreasing the collision of the power quality. On other side when distributed energy sources producing excess power, LES system can support the grid by storing the extra power from the sources. According to this portraiture, power system for grid connected PV systems with local energy storage system should work in multiple power flow as shown in Fig 1.

Numerous researches have been carried on dc-dc converter from past two decades. Therefore, this project is proposed on three port dc - dc converter (TPC), which has the ability to interface $\mathrm{PV}$ to DC bus with local energy storage system. Earlier work explains the benefits of TPC over single-input-single-output (SISO) structure such as greater efficiency, higher power density, less conversion stages. TPC are mainly of three groups: non-isolated, partially isolated where two ports commonly grounded, isolated topology.

Non isolated structure is commonly built from step-up and step-down converters such as buck and boost dc-dc converter topologies. The important benefits of nonisolated TPC against isolated and partially isolated structure are their greater efficiency and greater power density. Usually these structures are finding to be two independent topologies with common DC bus as shown in Fig 2.this gives less power when transferring to LES. 


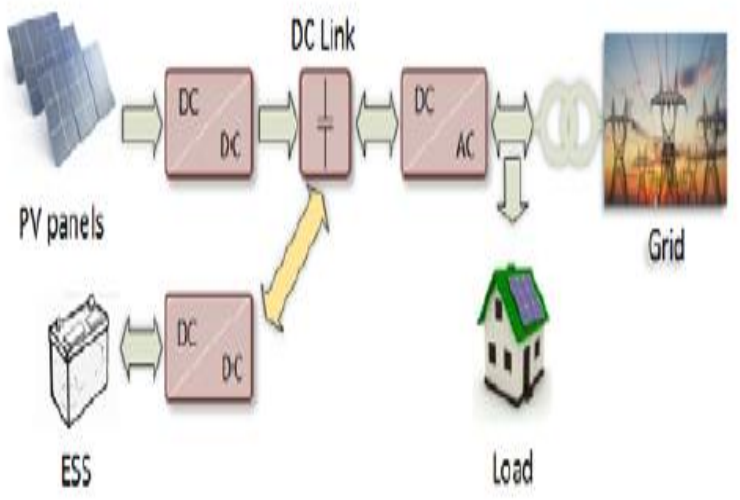

Fig.2. Block diagram of the traditional grid-connected PV plant with energy storage system (ESS) or LES

In order to reduce the power converting stages we approaching a very direct method commonly well know buck and boot converter for single power conversion as shown in Fig 3.

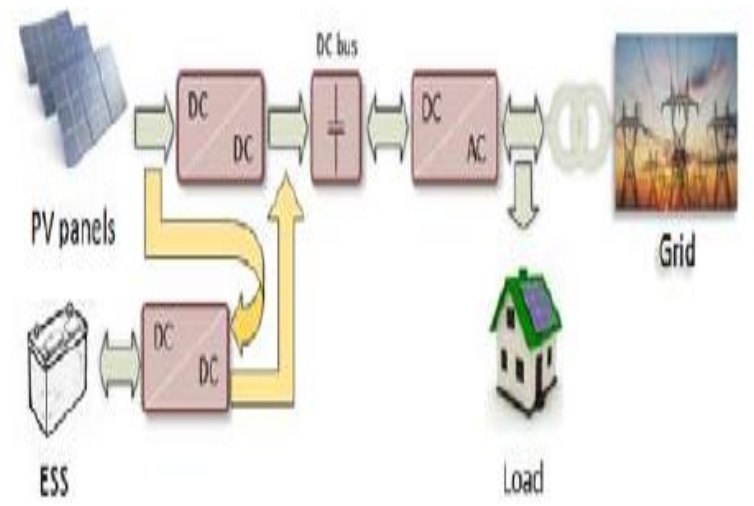

Fig.3. Block diagram of the proposed grid-connected PV plant with energy storage system (ESS) or LES.

Interleaving of buck boost topology is common to achieve greater power rating while decreasing the passive devices. Unequal current sharing and complex conversion stages can be solved by using these proposed topologies.

\section{PROPOSED TOPOLOGY}

The proposed structure is shown in Fig 4. This topology has three ports namely PV, load and battery. This gives single-input-single-output (SISO), Dual-input-singleoutput (DISO) and single-input-dual-output (SIDO) converter.

\section{A. Circuit Description}

The power converter is mainly achieved from common buck and boost topologies have high performance and efficiency under low voltage gain because of less passive component and power devices. Further deduce the power conversion stages by reduced modeling equation.
The important disadvantages of traditional buck and boost converter have their week performance for greater power and currents rating applications.

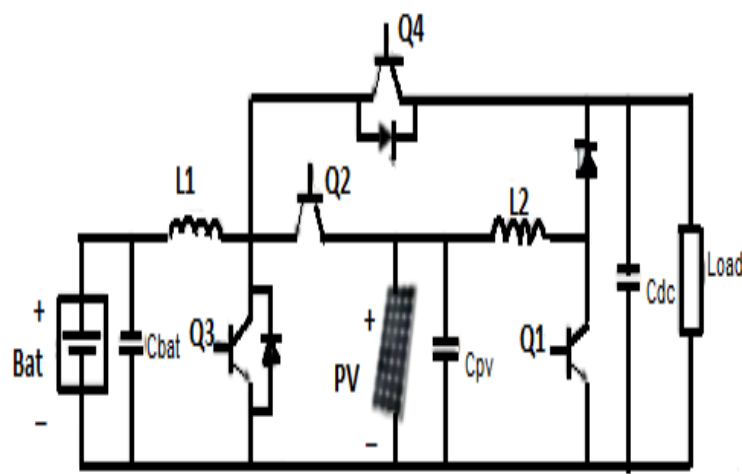

Fig.4Proposed TPC Topology

The other advantages while interleaving the buck and boost converter are (1) reduced putout ripple voltage and input current, (2) increasing efficiency at light loads, (3) power density can increase by using coupled magnetics.

The circuit consists of four power devices Q1, Q2, Q3 and Q4 they are controllable switches, can regulate the voltage and power flow at different stages. If switches are IGBT then freewheeling diodes can be used for D1and D2.External fast recovery diodes can be used for best result. Two inductors are essential; L1 is a part of boost stage while energy transfer from PV panel to the load and L2 is a part of buck stage where energy can transfer from PV to battery for charging and discharging. The input capacitors used for $\mathrm{PV}$ and battery are $\mathrm{C}_{\mathrm{PV}}$ and $\mathrm{C}_{\mathrm{Bat}}$ respectively and capacitor for $\mathrm{DC}$ bus is $\mathrm{C}_{\mathrm{DC}}$.

\section{B. Operational Principle}

The different modes of operation are illustrated in the Fig 6 . For the same mode of operation at most two power switches can be used, other two are in retired position. The different cases are explained bellow:

1. PV panel to load/grid (Fig 5a): when battery is fully charged and PV panels are generating the power can transfer the energy from panels to the grid or load trough boost converter L1-D1-Q1. Only one control signal d1is sufficient to regulate Q1.

2.PV panel to Battery (Fig 5b): When load is not required, battery can charge from PV panels through buck converter Q2-L2-D2.Here only one control signal d2 is enough for Q2.

3. Battery to grid/ load (Fig 5c): When there is no power from the PV panels, batteries will supply the required load demand through the boost converter L2-Q3-D3. Here also one control signal $\mathrm{d} 3$ is sufficient to control switch Q3. 


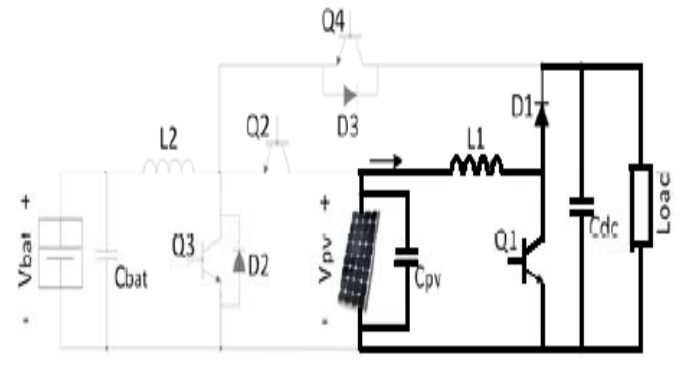

(a)

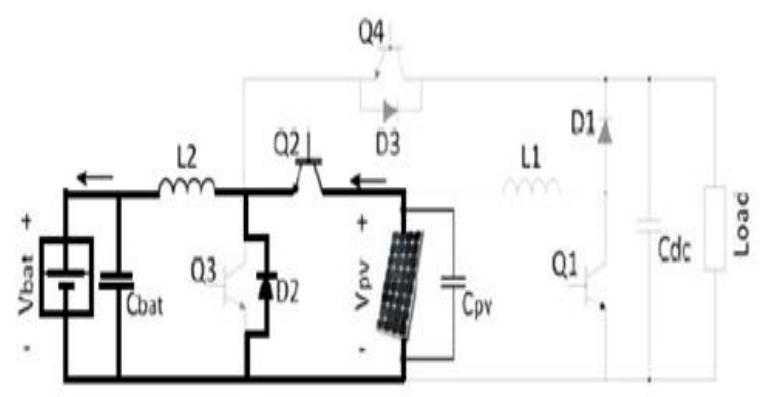

(b)

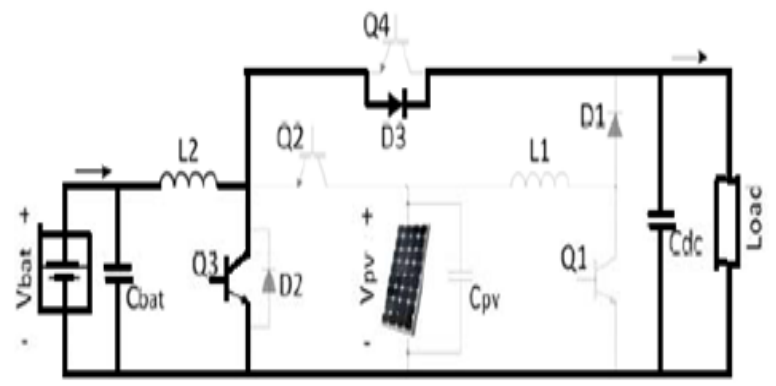

(c)

4. PV to load and battery (Fig 5d): When load requirement is less at that time the part of the power from PV panels is used to charge the battery and remaining part of the power is supplied to the load through both boost and buck converters L1-Q1-D1 and Q2-L2-D2 respectively. Control signals $\mathrm{d} 1$ and $\mathrm{d} 2$ are required to control $\mathrm{Q} 1$ and $\mathrm{Q} 2$ respectively.

5. PV, battery to load (Fig 5e): Whenever load demand is high, the power from both PV and battery will equals load demand through two boost stages L1-Q1-D1 and L1-Q3D3. Here $d 1$ and $d 3$ are the control signals to control the switches Q1 and Q3 respectively.

6. Grid to battery (Fig 5f): The excess amount of power in the grid from distributed energy source is used to charge the battery through buck stage Q4-L2-D2.one control signal d4 is enough to control the switch Q4.

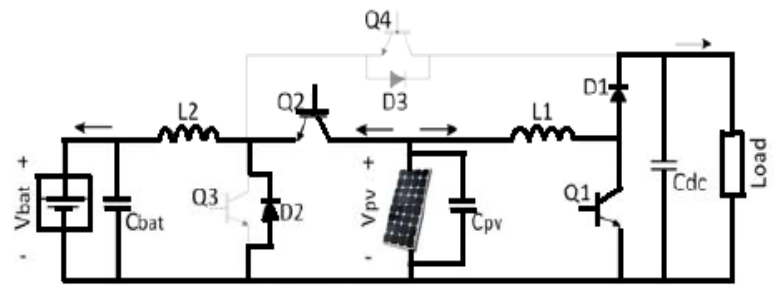

(d)

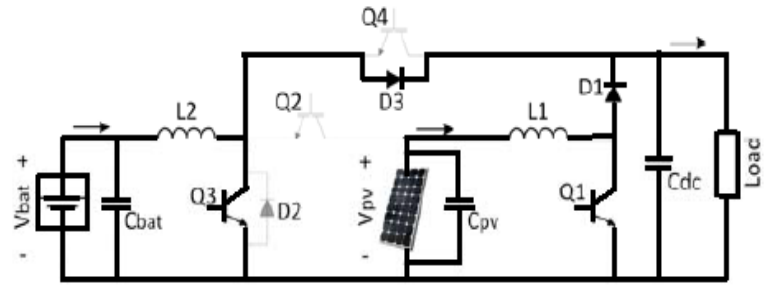

(e)

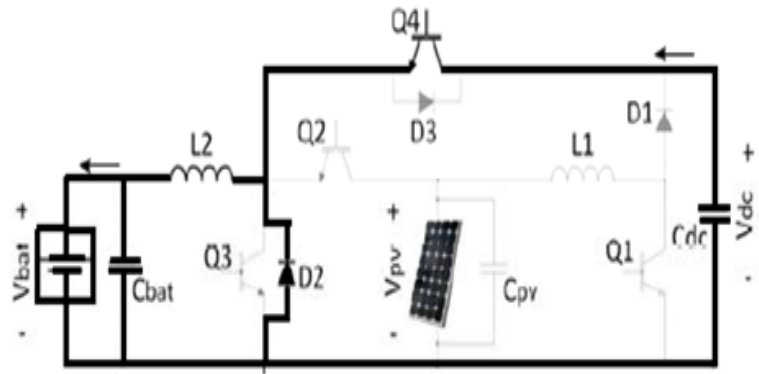

(f)

Fig.5. Operational circuitry for all operating modes, (a) PV to Load, (b) PV to Battery, (c) Battery and Load, (d) PV, Battery to Load, (e) PV to Battery, Load, (f) Battery charge from Grid.

\section{DESIGN PROCEDURE}

The suggested structure allows a simple design to carryout greater power level by combining both buck boost converters as previously explained. However, the interleaving of converter is considered for design equations.

\section{A. DC Voltage Gain}

The ideal converter is working under steady state and CCM, DC voltage gain is determined using volt-second law on inductors L1 and L2 for all conditions.

$\frac{\mathrm{Vdc}}{\mathrm{Vpv}}=\frac{1}{1-\mathrm{d} 1} \quad$ PV to Load

$\frac{\text { Vbat }}{\mathrm{Vpv}}=\mathrm{d} 2 \quad$ PV to Battery

$\frac{V d c}{V p v}=\frac{1}{1-d 3} \quad$ Battery to Load 
National Conference on Advances in Electrical Engineering

NMAM Institute of Technology, Nitte

Vol. 5, Special Issue 2, April 2017

$$
\frac{\text { Vbat }}{V d c}=\mathrm{d} 4 \quad \text { DC bus to Battery }
$$

The DC voltage and AC current can be calculated by using the below given equations.

$$
\begin{gathered}
I_{L 1, i}=\frac{I_{P V}}{n} \\
I_{L 2, i}=\frac{I_{b a t}}{n}=\frac{I_{P V}}{n \cdot d 1} \quad \text { PV to Battery } \\
I_{L 2, i}=\frac{I_{\text {bat }}}{n}=\frac{I_{d c}}{n \cdot(1-d 1)} \quad \text { Battery to load } \\
I_{L 2, i}=\frac{I_{b a t}}{n}=\frac{I_{d c}}{n \cdot d 2} \quad \text { DC bus toBattery } \\
V_{C p v}=V_{p v}=V_{d c}(1-d 1) \\
V_{C b a t}=V_{\text {bat }} \\
V_{C d c}=V_{\text {Load }}=V_{D C b u s}
\end{gathered}
$$

Where, $n=$ number of stages and $i=1 \ldots . . N$.

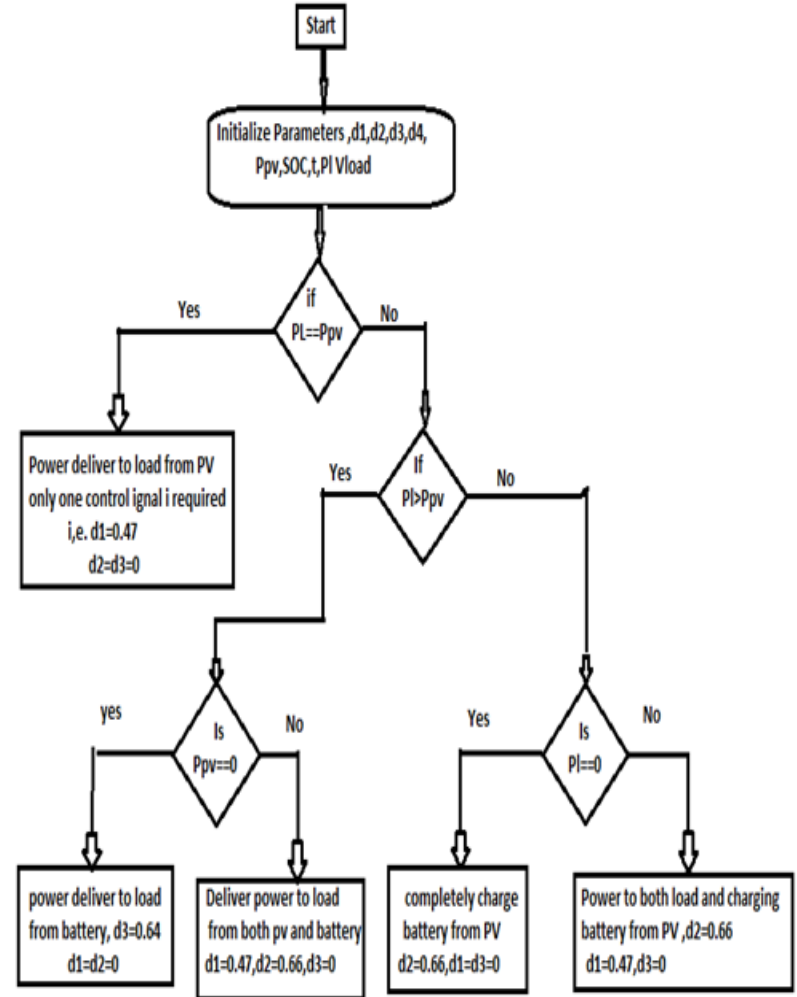

Fig.6 Flowchart for Operational Conditions

In above shown Fig 6 flowchart of all operating conditions with which control signal used to particular switch for different modes of operation.

\section{SIMULATION STUDY}

Simulation is done for a proposed circuit in MATLAB/SIMULINK as shown in Fig 7, taking the MOSFET as controllable switches for switching frequency of $25 \mathrm{kHz}$. The MATLAB functional block is used to generate code for different modes of operation, which will generate PWM pulses for all four switches considering resistive load.

The design values for $\mathrm{d} 1 \mathrm{~d} 2 \mathrm{~d} 3$ andd 4 are calculated by using well know Buck and Boost converters. The inductor L1 and L2 values are also calculated from same converters equation. Simulation is done for the values given in Table1.

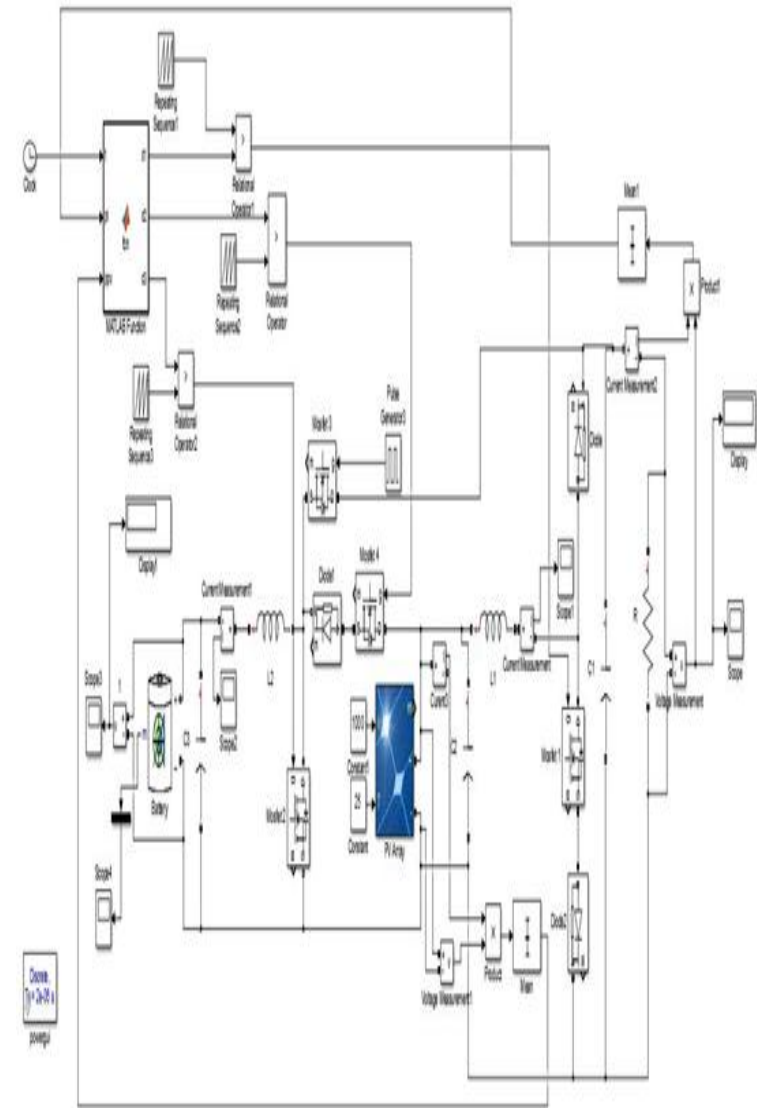

Fig.7 Simulation Circuit

TABLE I SYSTEM SPECIFICATIONS.

\begin{tabular}{|c|c|}
\hline Parameter & Values \\
\hline DC Bus Voltage & $34 \mathrm{~V}$ \\
\hline PV Voltage range & $18 \mathrm{~V}$ \\
\hline Battery Nominal Voltage & $12 \mathrm{~V}$ \\
\hline Max. output Power (DC bus) & $10 \mathrm{~W}$ \\
\hline Inductors: L1, L2 & $382.34 \mathrm{uH}, 300 \mathrm{uH}$ \\
\hline Switching Frequency & $25 \mathrm{KHz}$ \\
\hline Capacitors: C1,C2 & $250 \mathrm{uF}, 250 \mathrm{uF}$ \\
\hline
\end{tabular}


The simulation results shown in Fig 8, here are only for and grid tie application. This paper explains design the conditions PV to load and PV to battery, similarly for procedure and modes of operation. Buck and Boost other mode of operation, simulation is carried out with topologies are used in circuit so it is easy to design. The satisfying output.

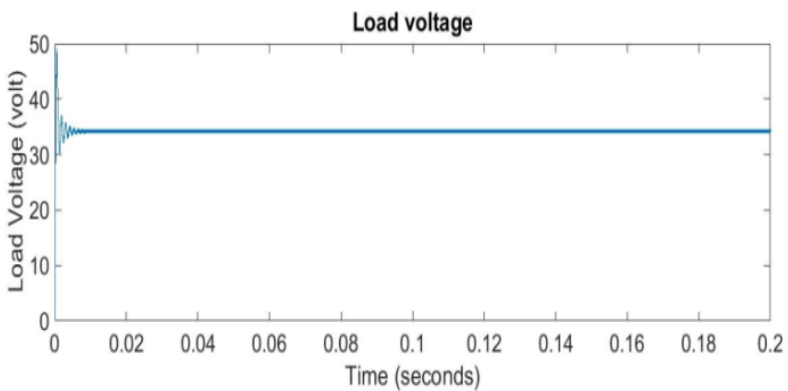

Fig.8(a) Simulated Load Output Voltage

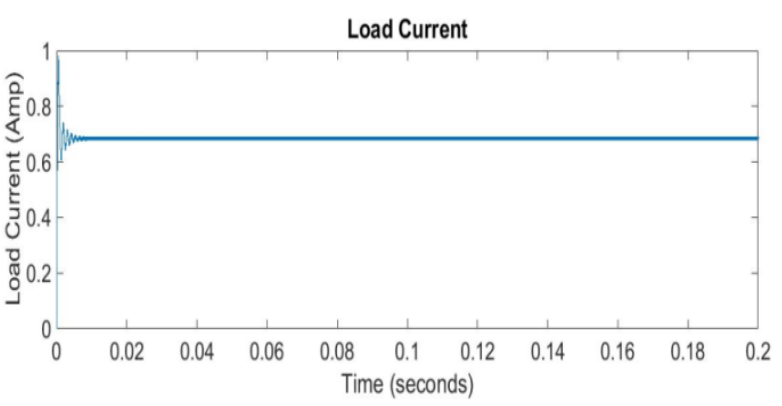

Fig.8 (b) Load Output Current

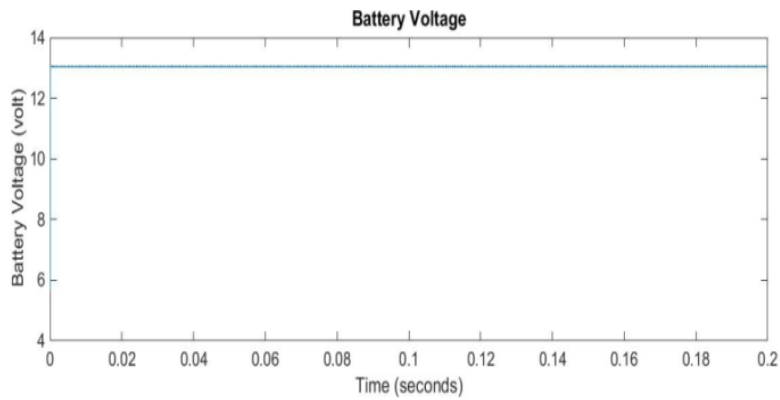

Fig.8 (c) Battery Voltage

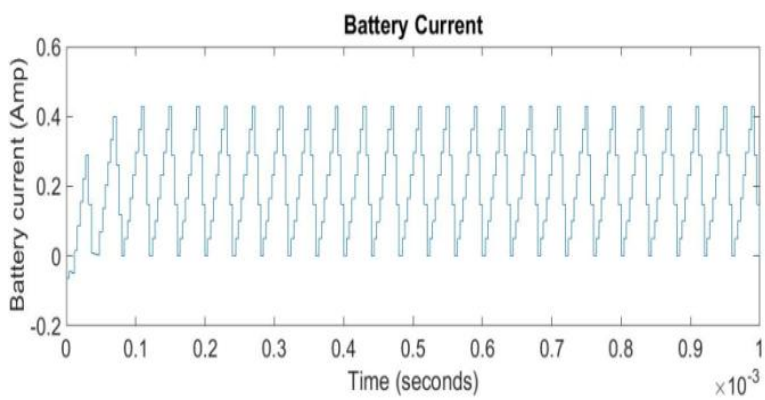

Fig.8 (d) Battery Current

\section{III.CONCLUSION}

The proposed DC-DC converter having the merits of usage for photovoltaic and battery to support household interleaving of converter will increase the power rating by reducing design complexity. Therefore this converter gives high efficiency for PV and Local energy storage systems and does not require galvanic isolation. Simulation is done in MATLAB/SIMULINK.

\section{ACKNOWLEDGMENT}

I express my deep gratitude to co-author Professor $\mathbf{K}$. Vasudeva Shettigar, Electrical and Electronics Engineering, NMAMIT Nitte. The author greatly Acknowledge to the department of Electrical and Electronics Engineering, NMAMIT Nitte, and R\&D department, Nitte. Also thankful to all those supported to complete the paper.

\section{REFERENCES}

[1] REN21, "Renewables 2015 Global Status Report," February 2015. [Online]. Available: http://www.ren21.net.

[2] Y. Cheng, "Impact of Large Scale Integration of Photovoltaic Energy Source and Optimization in Smart Grid with Minimal Energy Storage," IEEE International Symposium on Industrial Electronics, 2010.

[3] G. Mulder, F. De Ridder and D. Six, "Electricity storage for gridconnected household dwellings with PV panels," Solar Energy, vol. 84, no. 7, 2012

[4] S. Chiang, K. Chang and C. Yen, "Residential Photovoltaic Energy Storage System," IEEE Transactions on industrial electronics, vol. 45, no. 3, 1998

[5] H. Al-Atrash, F. Tian and I. Batarseh, "Tri-Modal Half-Bridge Converter Topology for Three-Port Interface," IEEE Transactions on Power Electronics, vol. 22, no. 1, pp. 341-345, 2007.

[6] Z. Wang, "An Integrated Three-Port Bidirectional DC-DC Converter for PV Application on a DC Distribution System," IEEE Transactions on Power Electronics, vol. 28, no. 10, pp. 4612-4624, 2012.

[7] H. Tao, A. Kotsopoulos, J. Duarte and M. Hendrix, "Family of multiport bidirectional DC-DC converters," IEEE Proceedings in Electric Power Applications, vol. 153, no. 3, 2006.

[8] D. Liu and H. Li, "A ZVS Bi-Directional DC-DC Converter for Multiple Energy Storage Elements," IEEE Transactions on Power Electronics, vol. 21, no. 5, 2006.

\section{BIOGRAPHIES}

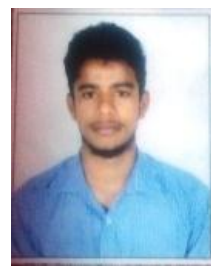

Rakesh M S, received his B.E (E\&E) degree from Shree Dharmasthala Manjunathewara Institute of technology, Ujjire, Belthangadi, India in 2014. He is pursuing his $\mathrm{M}$. Tech (Power Electronics) in Nitte Mahalinga Adyanthaya Memorial Institute of Technology, Nitte, Karkala, India. His area of interest includes Renewable energy research, Power Electronic and Power System technology. 
National Conference on Advances in Electrical Engineering

NMAM Institute of Technology, Nitte

Vol. 5, Special Issue 2, April 2017

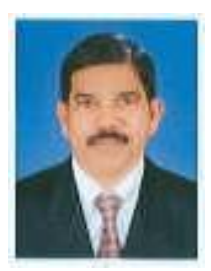

K. Vasudeva Shettigar, received his B.E. (E \& E) degree from SJCE, Mysore University, Mysore, India in 1986, and M.Tech. (Power Systems) degree in 1992 from National Institute of Engineering affiliated to Mysore University. Presently Mr. Vasudeva Shettigar is serving as Associate Professor, Dept. of Electrical \& Electronics Engineering, Nitte Mahalinga Adyanthaya Memorial Institute of Technology, Nitte, Karkala Karkala, India. He is Life member of ISTE. He has published 11 technical research papers in various National and International conferences. He has chaired International conference held at NMAMIT Nitte during May 2011, 2013 and 2015. Mr. Shettigar has organized several National Conferences and National Workshops and Short term training programmes (STTP) in the college for the benefit of faculty (NMAMIT) and faculty of neighboring Institutes. His areas of interest include power system \& protection, power quality and High Voltage Engineering. He has a teaching experience ofover 27 Years, and guided over 50 U.G \& 24 P.G. Technical Project works. 